\title{
Analysis of Puns in English Advertising Language From the Relevance Theory
}

\author{
YAN Yi-bo \\ Heze University, Heze, China
}

\begin{abstract}
The pun becomes the most popular language strategy for advertisers as a broadly used rhetorical device. Using pun words felicitously not only makes advertising language more humorous, implicative, and vivid but also leaves the audience a room to imagine and enjoy. The author summarizes pun's definitions, features, classifications, and how the pun procures a successful communicative activity in English advertisements based on Sperber and Wilson's Relevance Theory. At last, the pun's pragmatic functions are concluded.
\end{abstract}

Keywords: pun, advertising English, Relevance Theory, pragmatic functions

\section{Introduction}

The word "pun" comes from a Latin word "paronomasia", which means a humorous play on words. First, a word with two or more meanings, or two words with the same or similar sound are used in a pun. Second, there exists a literal meaning and an implied meaning in a pun.

The pun has two main characteristics, namely ambiguity and the double context.

The first feature of the pun is ambiguity. Leech (1983) has defined ambiguity as a kind language item which has two or more than two cognitive meanings. In spite of the fact that it is avoided in our daily communication as far as possible, the ambiguity is an effective way to attract the audience.

Another marked feature of the pun is double context. There are two meanings in a pun. One is the literal meaning; another is the intentional meaning. American scholar Archibald (1985) has put forward three elements in analyzing a pun, namely Double context, Hinge, and Trigger. "The pun is a hinge, a trigger refers to the intentions and backgrounds hide behind the exploitation of puns, which is often employed when we analyze the puns" (Archibald, 1985, pp. 449-450).

\section{Relevance Theory}

This paper adopts Relevance Theory as the theoretical foundation. The basic framework consists of mutual manifestness, context, ostensive-inferential communication, and optimal relevance. Relevance Theory points that human communicative activity is an ostensive-inferential communication.

\section{Ostensive-Inferential Communication}

The ostensive-inferential communication is an important development of Grice's inferential communication. Ostensive activity refers to the speaker, who shows his intention by making his utterance manifest to the hearer. There are two kinds of intentions in the process of ostension. One is the informative

YAN Yi-bo, lecturer, M.A., Foreign Language Department, Heze University. 
intention, which refers to "to make manifest or more manifest to the audience a set of assumption I" (Sperber \& Wilson, 1986, p. 58). Another is the communicative intention, which means "to make it mutually manifest to audience and communicator that the communicator has an informative intention I" (Sperber \& Wilson, 1995, p. $61)$.

Here is an example:

A: Would you like to have dinner with me?

B: I am headache.

In this example, A invites B to have a dinner, while B does not refuse A's invitation directly instead of saying he or she is headache. The informative intention is that B tells A he or she is headache and B knows this information. However, what is more important is that B wants $\mathrm{A}$ to know he or she has another intention and wants A to obtain the information by what he or she has expressed. At last, A gives up the invitation. This is the communicative intention. The act of B is a kind of ostensive behavior. While A gets the inference that B could not have dinner with him or her because of the headache. This process is a kind of ostensive-inference communication.

From the analysis of this simple example, it can be found that the ostensive-inferential communication involves two aspects. One is a stimulus of the speaker. The other is the inference of the listener. Therefore, communication is made up of the process of the speaker's stimulation or hint and the listener's inference. The audience obtains new information through hint of the speaker, form a contextual effect by combining their own cognitive context. This indicates human communication is a process of cognition and a process of ostensive-inferential communication.

According to Relevance Theory, the ostensive-inferential model suits any kinds of communications. However, advertising activity is also a kind of communicative activity. In spite of the fact that it is a kind of one-way communicative behavior, the advertising communication also follows the principle of ostensive-inferential communication.

\section{A Choice of Context}

Context is a very important concept of the Relevance Theory. It refers to a series of assumptions helping interpret an utterance in the deductive process. It is certain that the recipients cannot work out the explanation of an utterance without the support of the context. Because the recipients cannot handle the communicators' ostensive stimulus if there is no context. Sperber and Wilson hold an opinion that a context is chosen instead of being given, because the context is constructed in the process of comprehension rather than fixed in advance. And if a wrong context is chosen, the communication will fail. So, it is pretty significant to choose a right context. In the process of language communication, the audiences will choose, adjust, and extend the cognitive context by their existing logic knowledge and encyclopedic information. Besides, the context will not be chosen if it is not relevant to the utterance.

\section{Analysis of Advertising Pun in Different Types}

The types of puns have introduced before, including homophonic pun, semantic pun, grammatical pun, and idiomatic pun. Now, each type will be analyzed in order to understand how these puns make the communicative activity succeed. 


\section{Homophonic Pun}

The homophonic pun refers to a word having the same or similar sound with another one. There are two examples which contain such kind of pun.

Example 1: Haier and higher (An advertisement for Hair household appliances).

May be the audiences feel confused when they see the word "Haier", and they cannot find this word in any dictionary. This advertisement seems cannot make sense. At this time, if the customers repeat this advertisement again and again, they will find the word "Haier" has the same sound with the word "Higher". According to the Relevance Theory, the punning word "Haier" in this advertisement is the ostensive stimulus. It attracts audiences' attention and stimulates they continue to look for a further interpretation. When the audiences take advantage of their knowledge about Hair Company and context which this advertisement contains, they will have another understanding: The qualities and service of Hair will be higher and higher, better and better. From the homophonic pun, deep impression will be left in the audience's mind.

Here is the other piece of advertisement.

Example 2: Have a nice trip, buy-buy (An advertisement for a supermarket).

At first, the customers might consider the meaning of this advertisement is: "Enjoy your journey, bye-bye" because of "buy-buy" sounds same with "bye-bye" in the customers' cognitive contexts. But, if the context that it is an advertisement for a shop is taken into consideration, the customers will find this understanding is irrelevant to the literal meaning. Therefore, this explanation is denied. When having a second thinking, the customers can find the real intension of advertisers: They want consumers to buy something in this shop and wish customers will be satisfied with the quality of goods and the service of the shop. The understanding of this advertisement could be changed as follows: Shopping in our shop as happy as a journey, buy what you like.

In the above advertisements, the pun attracts customers' attention quickly by the similar sounds and the informative intention of the advertisement has usually been rejected. Then much more effort is needed in order to find its intended meaning.

\section{Semantic Pun}

Semantic pun means one word appears once or twice but it has two different meanings. "Many puns have a covert interpretation and one overt interpretation which searched for after reaching the covert one". (Yus, 2003, p. 132). At first glance, the advertisement is very ambiguous, the audiences do not understand what the advertisement wants to express. However, after thinking a while, the audience will remove the irrelevant meaning according to the certain context. This process is much longer and the efforts they pay will be larger. Here comes the analysis in detail.

Example 3: We suit you (An advertisement for a clothes shop).

The word "suit" in this advertisement has two parts of speech. One is verb, meaning "fit or satisfied". The other is noun, meaning "a set of clothes". If the audiences understand the word's meaning as "fit or satisfied", this sentence could make sense. The understanding would be: Our shop makes you feel satisfied. But, this explanation is not believable for the audiences because they could not understand what deserves customers' satisfaction. The customers will feel this advertisement is ambiguous. However, if the audiences remember another meaning of the word "suit", this advertisement's real intention becomes more clearly. It can be understood like this: We make suits for you. When the customer combines the two context meanings, another contextual effect is achieved: Our shop can provide a satisfied suit. Thus, the shop's image is presented to the 
customers. When the customers notice this advertisement, they can feel good quality and circumspect service. Another example is following.

Example 4: Whenever you shop at Four Square, you will like the change(An advertisement for a shop).

From this advertisement, the audiences can find the hinge or stimulus is the word "change". In a normal case, it refers to "alteration". With this common sense, the audiences will catch the key meaning: Whenever you shop at Four Square, the commodities are always new.

Then, the audiences realize that the word "change" has another meaning: "the money given back to customers". Different understandings will occur in the audiences' mind. They will adjust the context and get extra contextual effort: Whenever you shop at Four Square, you will get some money back.

The advertiser expresses double meanings to the audience by using a pun in this advertisement. However, the audiences find that both of two literal meanings are relevant and meaningful. Therefore, they combine the two meanings to form another contextual effort and it is the advertisers' real intention: Whenever you shop at Four Square, Four Square shop will supply you many new commodities and you will have a reasonable price.

In these examples, two meanings of one word are both taken into the understanding of the whole sentence. The two explanations are consistent with the principle of relevance, and they achieve a good contextual effect with moderate processing efforts. This kind of advertisement will be kept for a longer time in the audiences' mind.

\section{Grammatical Pun}

In English, each portion of the sentence has a grammatical role and in different contexts could have different meanings. Grammatical pun is a kind of pun which has grammatical uses. For instance, omitting some structures or some words has more than grammatical functions. Look at the following example.

Example 5: Coke refreshes you like no other can (An advertisement for Coca Cola).

In this advertisement, the ostensive stimulus is the word "can" because it has more than one grammatical function. This word catches customers' eyes successfully because it is special. It is certain that the word "can" has different parts of speech. When the customers consider the word "can" as a noun, the explanation of this advertisement could be: Coke refreshes you like no other can of drink.

While the customers consider it is a modal word, this sentence can give another interpretation: Coke refreshes you like no other drink can refresh you. Therefore, the customers could find that the Coca Cola's coke is the coolest drink and other's coke cannot compare to it. Thus, the pun makes this advertisement more attractive and believable. And it expresses much information for the customers. Although in this kind of pun, the audiences pay much processing efforts for handling the advertisement's information, they feel it is worthy because understanding such a pun is also funny and achievable.

\section{Idiomatic Pun}

Idioms and slangs can catch the audiences' eyes and they are very concise and economical. Therefore, many advertisers also make use of idioms or slangs as a way to make advertisement more interesting. They use similar or homophonic word to take place the original one. So, it can be used for an advertisement and achieve special effects. There are some examples about this type.

Example 6: An apple for everyone keeps worries away (An advertisement for Apple Computer).

In the first glance, the audiences will find this advertisement is very similar to an old popular saying: An apple a day keeps doctors away. And it seems to tell the audiences that: If you eat an apple every day, there is 
nothing to worry about boring.

But, it is the informative intention of this advertisement, which is not relevant to the audiences and more efforts are needed to obtain the communicative intention. The audiences change another context when they notice it is an advertisement for Apple Company. Then the audiences understand that this advertisement wants to express such a context meaning: If you buy Apple electronic products, you will feel the fun and do not worry about the boring.

From these six examples, this part has analyzed how the audiences achieve the optimal relevance by the pun; find the real intentions of the advertisers. The pun as a kind of ostensive stimuli attracts the audiences' attention and seeks the optimal relevance.

\section{Major Findings}

\section{Arousing Attention}

A successful advertisement needs attracting the audiences' attention. If consumers are interested in the advertisement when they first notice it, the advertisers have a good chance to persuade the potential consumers to buy their products or service. The pun can arouse the audiences' attention because it contains ambiguity. It gives the audiences a puzzle, and then they will wonder what this advertisement means. Another reason is the humorous effect.

\section{Making Advertisement More Brief}

Advertising space is costly. Economy is essential. Puns are highly economical (two meanings for the price of one word or phrase) and are in fact much more of a space - saving device than many of the products they seek to promote. (Tanaka, 1994, pp. 37-39)

Tanaka has proposed that using a pun can save the space for it conveys two meanings with one word. Besides, with the development of the society, the pressure of life increases constantly. People are unwilling to spend so much effort on tedious advertisements. Therefore, brief advertisement is more necessary. A pun in an advertisement could express much information in less word for its dual meanings conveyed in a signal word.

\section{Acquiring Aesthetic Feeling}

The pun is a type of figure of speech. Using pun words in the advertisement can make the language acquire aesthetic effect. When the audiences compare the advertisement which contains a pun with another one, they must have different feelings. If there is no any figure of speech in an advertisement, the audiences will consider the advertisement lack of some influence. While using a pun is different, the audiences believe that the advertiser is gifted when using pun words. It is certain that people prefer reading the graceful sentence than boring sentence.

\section{Avoiding Social Taboos}

There are many taboos in our society. Taboo is something strongly forbidden because of custom, belief, or something else. Advertisement as a kind of language for information conveying, some negative or bad words should not occur in it. While using a pun could present some information implicitly. The embarrassing information could be expressed by a pun because of two context meanings. Therefore, the pun in advertisement is very useful and convenient to avoid social taboos. 


\section{Conclusion}

With the guidance of the Relevance Theory, this paper analyzed how the advertising communicative activity succeeds by using pun words. The advertisers make use of the pun as ostensive stimuli to express the informative intention and the customers take use of their cognitive ability to find the communicative intention. Using a pun in an advertisement is more attractive to the audiences, because puns are humorous, wise, and implicative. Besides, the question why puns are still preferred by so many advertisers although they are ambiguous is also answered. The reason is that pun words can eliminate the superficial meaning and endow the implication of the utterance. Then, the author concluded some pragmatic functions of pun, including arousing the audiences' attention, making the advertisement more brief, acquiring aesthetic feeling, and avoiding social taboos. And this study could offer some guidance to advertisers to invent better advertisements. What is more, people might pay more attention to puns and use it in daily communication.

\section{References}

Archibald, A. H. (1970). Puns: Their reality and their uses. International Journal of American Linguistics, 4,110-116.

Geis, M. L. (1986). The language of television advertising. New York: Academic Press.

Hornby, A. S. (1997). The Oxford English dictionary. Oxford: Oxford University Press.

Leech, G. N. (1983). Principles of pragmatics. Cambridge: Cambridge University Press.

Longman dictionary of the English language. (1984). London: World Publishing Corp.

McQuarrie, E. F., \& Mick, G. M. (1996). Figures of rhetoric in advertising language. Journal of Consumer Research, 22, 424-438.

Sperber, D., \& Wilson, D. (1986). Relevance: Communication and cognition. Cambridge: Harvard University Press.

Sperber, D., \& Wilson, D. (1995). Relevance: Communication and cognition. Oxford: Blackwell.

Sperber, D., \& Wilson, D. (2001). Relevance: Communication and cognition (2nd ed.). Beijing: Foreign Language Teaching and Research Press.

Tanaka, K. (1994). Advertising language: A pragmatic approach to advertisements in Britain and Japan. London: Routledge.

Webster's third international dictionary. (1961). Springfield: Merriam-Webster.

Yus, F. (2003). Humor and the search for relevance. Journal of Pragmatics, 35, 132. 